\title{
Postoperative delirium in patients undergoing tumor resection with reconstructive surgery for oral cancer
}

\author{
NOZOMU TAKAHASHI ${ }^{1}$, AKIMITSU HIRAKI ${ }^{2}$, KENTA KAWAHARA $^{1}$, MASASHI NAGATA $^{1}$, RYOJI YOSHIDA $^{1}$, \\ YUICHIRO MATSUOKA ${ }^{1}$, TAKUYA TANAKA ${ }^{1}$, YUKO OBAYASHI ${ }^{2}$, JUNKI SAKATA ${ }^{1}$, HIKARU NAKASHIMA ${ }^{1}$, \\ HIDETAKA ARITA $^{1}$, MASANORI SHINOHARA ${ }^{3}$ and HIDEKI NAKAYAMA ${ }^{1}$ \\ ${ }^{1}$ Department of Oral and Maxillofacial Surgery, Faculty of Life Sciences, Kumamoto University, Kumamoto 860-8556; \\ ${ }^{2}$ Section of Oral Oncology, Department of Oral and Maxillofacial Surgery, Fukuoka Dental College, \\ Fukuoka 814-0193; ${ }^{3}$ Itoh Dento-Maxillofacial Hospital, Kumamoto 860-0851, Japan
}

Received May 22, 2020; Accepted September 25, 2020

DOI: $10.3892 / \mathrm{mco} .2021 .2222$

\begin{abstract}
Many attempts have been made to identify the risk factors for postoperative delirium, but this has proved difficult due to its complex morbidity. Furthermore, there is little information on postoperative delirium in patients undergoing tumor resection and reconstructive surgery for oral cancer. The aim of the current study was to investigate the incidence of and risk factors for postoperative delirium in patients undergoing resection and reconstructive surgery for oral cancer. The present study included 104 patients with pedicle or free flap reconstruction. Postoperative delirium developed in $22(21.2 \%)$ of these patients. The mean time to onset of postoperative delirium was $2.5 \pm 1.0$ days and the duration of delirium was $1.9 \pm 1.2$ days. Univariate analysis demonstrated that the occurrence of postoperative delirium was significantly correlated with operating time $(\mathrm{P}=0.033)$, duration of anesthesia $(\mathrm{P}=0.039)$, amount of blood loss $(\mathrm{P}=0.027)$, method of reconstruction $(\mathrm{P}=0.008)$, type of flap used $(\mathrm{P}=0.009)$ and time until postoperative ambulation $(\mathrm{P}=0.0008)$. Low postoperative red blood cell count $(\mathrm{P}=0.004)$, hemoglobin $(\mathrm{P}=0.004)$ and hematocrit $(\mathrm{P}=0.004)$ were significantly associated with delirium, but preoperative blood test results were not. The multiple logistic regression analysis of these risk factors revealed that the only significant correlation that remained was between postoperative delirium and the time to ambulation after surgery $(\mathrm{P}=0.005)$. Since 2009, the Department of Oral and Maxillofacial Surgery, Kumamoto University Hospital has promoted ambulation after the first two postoperative days for patients with oral cancer undergoing tumor resection with reconstruction, and the occurrence of postoperative delirium
\end{abstract}

Correspondence to: Professor Akimitsu Hiraki, Section of Oral Oncology, Department of Oral and Maxillofacial Surgery, Fukuoka Dental College, 2-15-1 Tamura, Sawara-ku, Fukuoka 814-0193, Japan E-mail: hiraki@college.fdcnet.ac.jp

Key words: early postoperative ambulation, oral cancer, postoperative delirium, reconstructive surgery, tumor resection has decreased from 29.2 to $14.0 \%$. The results of the current study suggest that early postoperative ambulation in patients who undergo reconstructive surgery for oral cancer is effective for preventing postoperative delirium.

\section{Introduction}

The oral cavity is important for pronunciation, swallowing, and digestion, and its function is essential for daily living. Advanced oral cancer entails a substantial loss of tissue after resection, which often leads to decreased quality of life postoperatively; therefore, reconstruction after tumor resection is important for quality of life in these patients. However, tumor resection and reconstructive surgery requires comparatively long operating and anesthesia times, which can lead to pneumonia, deep vein thrombosis, pressure areas, and postoperative delirium associated with prolonged bed rest. These complications can impede medical treatment and postoperative recovery $(1,2)$. Postoperative delirium is a common and serious surgical complication that is defined as a change in mental status caused by a physical problem associated with surgery. Postoperative delirium is characterized by impaired consciousness, including a reduced ability to focus attention, changes in cognitive function, altered perception, and disturbed sleep-wake cycles. In addition, it has an acute onset and a fluctuating course (3).

Delirium is classified into three motor subtypes: Hyperactive/agitated (e.g. self-removal of intravenous line or gastric tube, rampage without self-control), hypoactive/ somnolent (e.g. disorientation, hallucination), and mixed; the mixed type fluctuates between the hyperactive and hypoactive types during the course of the illness $(3,4)$. Most patients with postoperative delirium recover rapidly; however, the condition is associated with increased morbidity, a prolonged hospital stay, higher economic costs, and increased mortality $(3,5-8)$.

Many researchers have sought to clarify the risk factors for postoperative delirium but the specific features and risk factors are difficult to identify because of its complex morbidity (9-11). There are few reports on postoperative delirium in patients undergoing tumor resection and reconstructive surgery for oral cancer. Thus, the aim of this study was to identify the 
clinical risk factors associated with postoperative delirium in patients undergoing tumor resection and reconstructive surgery for oral cancer.

\section{Materials and methods}

Patients and methods. This study had a non-randomized, retrospective cohort design and the data analyzed were collected from medical records. One hundred and four patients who had undergone tumor resection with reconstructive surgery for oral cancer in the Department of Oral and Maxillofacial Surgery, Kumamoto University Hospital, between January 2005 and December 2012 were enrolled. All patients underwent surgery by the same operator. The study population comprised 72 men and 32 women of mean age 63.0 (range 17-84) years. The primary tumor sites were the tongue in 38 patients, the lower gingiva in 38 , the floor of the mouth in 13 , the buccal mucosa in 9 , and the upper gingiva in 6. One patient had a history of depression and eight had insomnia. Delirium was diagnosed by a psychiatrist according to the criteria outlined in the Text Revision of the Diagnostic and Statistical Manual of Mental Disorders, 4th edition. If it appeared that a patient had a mental disturbance, the psychiatrists were consulted to determine if there was a need for psychotropic medication, and the patient was diagnosed with delirium by the psychiatrist. The patients were not all diagnosed by the same psychiatrist. Recovery from delirium were retrospectively determined with reference to the medical records. The day of recovery from delirium was defined as either the time at which the symptoms of suspected delirium disappeared, or the patient discontinued drug therapy for delirium. All patients received fentanyl citrate $0.3 \mu \mathrm{g} / \mathrm{kg} / \mathrm{h}$ during the first $24 \mathrm{~h}$ postoperatively for pain relief, and only non-steroidal anti-inflammatory drugs or acetaminophen were used depending on the patient's pain level thereafter. None of the patients required mechanical ventilation. Thirteen patients were returned to a general ward after a 2-7-day stay in the high dependency unit but none entered the intensive care unit. Insomnia was treated with either etizolam or hydroxyzine, but major and minor tranquilizers were not used routinely. The study protocol was approved by the institutional review board of Kumamoto University (RINRI no. 1928) and conducted in accordance with the Declaration of Helsinki. The requirement for informed consent was waived due to the retrospective design of the study. However, patients were given the opportunity to decline participation via an opt-out route.

Variables investigated. We analyzed the following variables: Preoperative factors, including age, sex, TNM classification, stage classification, histologic type, smoking status, and alcohol consumption in the 3 months prior to surgery; intraoperative factors, including operating and anesthesia times, amount of blood loss, blood transfusion requirements, presence of tracheotomy, method of reconstruction (free vs. pedicle flap), and type of flap used; postoperative ambulation; and flap engraftment. At our institution, until 2009, patients undergoing tumor resection with reconstructive surgery for oral cancer were kept on complete bed rest for a week after surgery; thereafter, we encouraged ambulation after the first two postoperative days. For this study, we divided the patients according to whether they were treated before ( $n=48$, non-early ambulation group) or after ( $n=56$, early ambulation group) the cut-off of 2009. Preoperative blood tests, including hematology and biochemistry, were performed within 7 days of surgery. Postoperative blood tests were performed on the day after surgery. Data for all of these parameters are listed in Tables I-V.

Statistical analysis. All statistical analyses were performed using JMP9 software (SAS Institute, Inc.). The Mann-Whitney U test was used to compare continuous variables and Fisher's exact test was used to compare categorical variables. Variables that achieved significance in the univariate analysis were entered into a multivariate analysis to estimate the risk of postoperative delirium. Multiple logistic regression analysis was used to adjust for multiple risk factors and interactions. P-values less than 0.05 were considered statistically significant.

\section{Results}

Incidence of postoperative delirium. The 22 patients (21.2\%) who developed postoperative delirium comprised 16 men and 6 women of mean age $66 \pm 11.0$ (range $38-82$ ) years. The time to onset of postoperative delirium ranged from 1 to 5 days after surgery, with a mean onset at $2.5 \pm 1.0$ days (median 2 days). The mean duration of delirium was $1.9 \pm 1.2$ days. Ten patients developed hyperactive/agitated delirium, six developed hypoactive/somnolent delirium, and six developed mixed-type delirium. There were instances in which patients with hyperactive or mixed-type delirium removing their nasogastric tube (eight cases), intravenous line (five cases), or drainage tube (one case). Some of the patients with hypoactive or mixed-type delirium experienced hallucinations (seven cases) and disorientation (nine cases). Delirium occurred in three patients with a history of insomnia, but not in any of those with a history of depression.

Risk factors in univariate analyses. The results of univariate analyses seeking to identify significant associations between demographic and clinical factors and occurrence of postoperative delirium are shown in Tables I-III. There was no significant correlation between the occurrence of postoperative delirium and any of the preoperative risk factors. There were significant associations between the occurrence of postoperative delirium and certain intraoperative factors, including operating time $(\mathrm{P}=0.033)$, duration of anesthesia $(\mathrm{P}=0.039)$, blood loss $(\mathrm{P}=0.027)$, method of reconstruction $(\mathrm{P}=0.008)$, and type of flap used $(\mathrm{P}=0.009)$. Significantly more patients who underwent free flap reconstruction developed symptoms of postoperative delirium than those who underwent pedicle flap reconstruction $(30.9 \%$ [17/55] vs. $10.2 \%$ [5/49]; $\mathrm{P}=0.008)$. The highest incidence of postoperative delirium occurred in patients who underwent forearm flap (37.5\%) or scapular osteocutaneous flap (33.3\%) reconstruction; in contrast, none of the patients who underwent cervical island myocutaneous flap or deltopectoral flap reconstruction experienced postoperative delirium. Although there was no statistically significant difference, the delirium incidence rate was clearly reduced in the early ambulation group compared with the non-early ambulation group (14.0\% [8/56] vs. 29.2\% [14/48]; $\mathrm{P}=0.053)$. The time to ambulation after surgery in the non-early ambulation group and early ambulation group was 4.6 and 3.1 days, respectively. Univariate analyses revealed a significant 
Table I. Preoperative factors and incidence of postoperative delirium.

\begin{tabular}{|c|c|c|c|c|}
\hline Preoperative factor & Case & Delirium $(\mathrm{n}=22), \mathrm{n}(\%)$ & No delirium $(\mathrm{n}=82), \mathrm{n}(\%)$ & P-value \\
\hline \multicolumn{5}{|l|}{ Age } \\
\hline Mean \pm standard deviation & & $66.0 \pm 11.0$ & $62.0 \pm 13.0$ & 0.23 \\
\hline Sex & & & & 0.45 \\
\hline Male & 72 & $16(72.7)$ & $56(68.3)$ & \\
\hline Female & 32 & $6(27.3)$ & $26(31.7)$ & \\
\hline T classification $^{\mathrm{a}}$ & & & & 0.90 \\
\hline $\mathrm{T} 1$ & 0 & $0(0)$ & $0(0)$ & \\
\hline $\mathrm{T} 2$ & 18 & $3(17.6)$ & $15(22.4)$ & \\
\hline $\mathrm{T} 3$ & 25 & $5(29.4)$ & $20(29.9)$ & \\
\hline $\mathrm{T} 4$ & 41 & $9(52.9)$ & $32(47.8)$ & \\
\hline $\mathrm{N}$ classification ${ }^{\mathrm{a}}$ & & & & 0.54 \\
\hline No & 14 & $3(17.6)$ & $11(16.4)$ & \\
\hline N1 & 15 & $1(5.9)$ & $14(20.9)$ & \\
\hline $\mathrm{N} 2 \mathrm{~b}$ & 43 & $10(58.8)$ & $33(49.3)$ & \\
\hline $\mathrm{N} 2 \mathrm{c}$ & 12 & $3(17.6)$ & $9(13.4)$ & \\
\hline M classification ${ }^{\mathrm{a}}$ & & & & Not done \\
\hline M0 & 84 & 0 & 0 & \\
\hline Staging classification $^{\mathrm{a}}$ & & & & 0.67 \\
\hline Stage I & 0 & 0 & 0 & \\
\hline Stage II & 3 & $0(0)$ & $3(4.5)$ & \\
\hline Stage III & 13 & $3(17.6)$ & $11(16.4)$ & \\
\hline Stage IV & 68 & $14(82.4)$ & $53(79.1)$ & \\
\hline Histologic type & & & & 0.57 \\
\hline Squamous cell carcinoma & 96 & $21(95.5)$ & $76(89.4)$ & \\
\hline Adenoid cystic carcinoma & 4 & $1(4.5)$ & $3(3.5)$ & \\
\hline Sarcoma & 4 & $0(0)$ & $4(4.7)$ & \\
\hline Smoking status & & & & 0.47 \\
\hline Smoker & 35 & $8(36.4)$ & $27(32.5)$ & \\
\hline Non-smoker & 69 & $14(63.6)$ & $55(67.5)$ & \\
\hline Alcohol consumption & & & & 0.14 \\
\hline Drinker & 53 & $14(63.6)$ & $39(47.6)$ & \\
\hline Non-drinker & 51 & $8(36.4)$ & $43(52.4)$ & \\
\hline
\end{tabular}

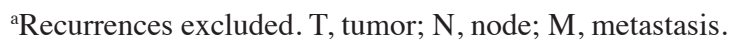

correlation between the incidence of postoperative delirium and the time to postoperative ambulation $(\mathrm{P}=0.0008)$.

Analysis of laboratory data. The laboratory data are summarized in Tables IV and V. There were no significant differences in the laboratory parameters preoperatively (Table IV), but significant correlations were found between the occurrence of postoperative delirium and red blood cell count $(\mathrm{P}=0.004)$, hemoglobin $(\mathrm{P}=0.004)$, and hematocrit $(\mathrm{P}=0.004)$ postoperatively. There was no significant correlation between any of the other laboratory parameters postoperatively and the occurrence of postoperative delirium (Table V).

Risk factors in multivariate analyses. Variables identified to have a significant correlation with the incidence of postoperative delirium in univariate analyses were then tested in a multivariate analysis. A significant correlation was found between the occurrence of postoperative delirium and the time to ambulation after surgery $(\mathrm{P}=0.005$; Table VI). There was no significant correlation between the occurrence of postoperative delirium and any of the other risk factors.

Treatments for postoperative delirium. Seventeen of the 22 patients diagnosed to have postoperative delirium received medication as their initial treatment. Five patients received haloperidol ( $5 \mathrm{mg}$, intramuscularly), four received hydroxyzine ( $25 \mathrm{mg}$, intravenously), three received etizolam (0.5 mg, orally), five received haloperidol (5 mg, intramuscularly) plus hydroxyzine ( $25 \mathrm{mg}$, intravenously) and five received only strict follow-up. Only two patients required 
Table II. Intraoperative factors and incidence of postoperative delirium.

\begin{tabular}{|c|c|c|c|c|}
\hline Intraoperative factor & Case & $\begin{array}{c}\text { Delirium }(\mathrm{n}=22) \\
\mathrm{n}(\%)\end{array}$ & $\begin{array}{c}\text { Non-delirium }(\mathrm{n}=82) \\
\mathrm{n}(\%)\end{array}$ & P-value \\
\hline Operating time (min) & & & & 0.033 \\
\hline Mean \pm SD & & $654 \pm 167$ & $576 \pm 161$ & \\
\hline Anesthesia time (min) & & & & 0.039 \\
\hline Mean \pm SD & & $772 \pm 149$ & $699 \pm 159$ & \\
\hline Blood loss (ml) & & & & 0.027 \\
\hline Mean \pm SD & & $608 \pm 256$ & $492 \pm 331$ & \\
\hline Blood transfusion & & & & 0.490 \\
\hline Received & 40 & $9(22.5)$ & $31(77.5)$ & \\
\hline Not received & 64 & $13(20.3)$ & $51(79.7)$ & \\
\hline Tracheotomy & & & & 0.510 \\
\hline Received & 54 & $11(20.4)$ & $43(79.6)$ & \\
\hline Not received & 50 & $11(22.0)$ & $39(78.0)$ & \\
\hline Method of reconstruction & & & & 0.008 \\
\hline Free flap & 55 & $17(30.9)$ & $38(69.1)$ & \\
\hline Pedicle flap & 49 & $5(10.2)$ & $44(89.8)$ & \\
\hline Type of flap & & & & 0.009 \\
\hline Forearm flap & 24 & $9(37.5)$ & $15(62.5)$ & \\
\hline Scapular osteocutaneous flap & 9 & $3(33.3)$ & $6(66.7)$ & \\
\hline Rectus abdominis musculocutaneous flap & 22 & $5(22.7)$ & $17(81.8)$ & \\
\hline Latissimus dorsi flap & 30 & $4(13.3)$ & $26(86.7)$ & \\
\hline Pectoralis major myocutaneous flap & 13 & $1(7.7)$ & $12(92.3)$ & \\
\hline Cervical island myocutaneous flap & 4 & $0(0)$ & $4(100.0)$ & \\
\hline Deltopectoral flap & 2 & $0(0)$ & $2(100.0)$ & \\
\hline
\end{tabular}

SD, standard deviation.

Table III. Postoperative factors and incidence of postoperative delirium.

\begin{tabular}{|c|c|c|c|c|c|}
\hline Postoperative factor & Case & Duration of ambulation & Delirium $(n=22)$ & Non-delirium $(\mathrm{n}=82)$ & P-value \\
\hline \multicolumn{6}{|l|}{ Postoperative ambulation (days) } \\
\hline Mean \pm standard deviation & 104 & $3.7 \pm 1.8$ & $5.1 \pm 2.0$ & $3.4 \pm 1.6$ & $<0.001$ \\
\hline Non-early ambulation group & 48 & $4.6 \pm 1.9$ & 14 & 34 & 0.053 \\
\hline Early ambulation group & 56 & $3.1 \pm 1.3$ & 8 & 48 & \\
\hline Flap engraftment, n (\%) & & & & & 0.290 \\
\hline Engraftment & 95 & & $19(86.4)$ & $76(92.7)$ & \\
\hline Necrosis & 9 & & $3(13.6)$ & $6(7.3)$ & \\
\hline
\end{tabular}

SD, standard deviation.

physical restraint. The five patients who received only strict follow-up recovered gradually from delirium. The patients who required physical restraint showed extreme agitation and communication difficulties. The four remaining patients did not recover from their delirium promptly; however, three eventually recovered after receiving additional medications, including haloperidol ( $5 \mathrm{mg}$, intramuscularly); and one recovered after receiving levomepromazine (15 $\mathrm{mg}$, orally) and diazepam (5 mg, orally).

\section{Discussion}

Postoperative delirium often leads to pneumonia, deep vein thrombosis, and pressure areas that impede medical treatment and postoperative recovery. The risk of postoperative delirium depends on the type of surgery (12). The rates reported for major surgical procedures are comparatively high at 21-60\% for those undergoing hip fracture surgery (13) and 30-73\% for those undergoing open heart surgery $(3,8,14-17)$. Postoperative 
Table IV. Preoperative laboratory data.

\begin{tabular}{|c|c|c|c|}
\hline Laboratory data & Delirium (mean $\pm \mathrm{SD}$ ) & Non-delirium $($ mean $\pm \mathrm{SD})$ & $\mathrm{P}$-value \\
\hline White blood cell count $\left(10^{3} / \mu \mathrm{l}\right)$ & $4.65 \pm 1.28$ & $5.10 \pm 1.84$ & 0.471 \\
\hline Red blood cell count $\left(10^{6} / \mu \mathrm{l}\right)$ & $3.65 \pm 0.52$ & $3.92 \pm 0.55$ & 0.052 \\
\hline Hemoglobin $(\mathrm{g} / \mathrm{dl})$ & $11.50 \pm 1.48$ & $12.29 \pm 1.71$ & 0.092 \\
\hline Hematocrit (\%) & $34.63 \pm 3.80$ & $36.94 \pm 4.84$ & 0.056 \\
\hline Sodium (mEq/l) & $139.27 \pm 2.30$ & $139.63 \pm 3.11$ & 0.181 \\
\hline Potassium (mEq/l) & $4.38 \pm 0.39$ & $4.31 \pm 0.40$ & 0.642 \\
\hline Chlorine (mEq/l) & $105.0 \pm 3.55$ & $104.78 \pm 2.77$ & 0.711 \\
\hline Total protein $(\mathrm{g} / \mathrm{dl})$ & $6.88 \pm 0.61$ & $6.67 \pm 0.55$ & 0.192 \\
\hline Albumin $(\mathrm{g} / \mathrm{dl})$ & $3.85 \pm 0.39$ & $3.91 \pm 0.47$ & 0.511 \\
\hline Blood urea nitrogen (mg/dl) & $15.23 \pm 4.21$ & $13.52 \pm 4.13$ & 0.096 \\
\hline Creatinine (mg/dl) & $0.75 \pm 0.20$ & $0.72 \pm 0.16$ & 0.937 \\
\hline Total bilirubin (mg/dl) & $0.69 \pm 0.27$ & $0.64 \pm 0.29$ & 0.433 \\
\hline Aspartate aminotransferase (IU/l) & $22.32 \pm 9.60$ & $21.71 \pm 11.91$ & 0.625 \\
\hline Alanine aminotransferase (IU/l) & $22.36 \pm 17.68$ & $18.73 \pm 10.99$ & 0.369 \\
\hline
\end{tabular}

$\mathrm{SD}$, standard deviation.

Table V. Postoperative laboratory data.

\begin{tabular}{|c|c|c|c|}
\hline Laboratory data & Delirium (mean $\pm \mathrm{SD}$ ) & Non-delirium $($ mean $\pm \mathrm{SD})$ & P-value \\
\hline White blood cell count $\left(10^{3} / \mu 1\right)$ & $12.05 \pm 3.90$ & $11.72 \pm 3.86$ & 0.759 \\
\hline Red blood cell count $\left(10^{6} / \mu 1\right)$ & $3.09 \pm 0.34$ & $3.40 \pm 0.44$ & 0.004 \\
\hline Hemoglobin (g/dl) & $9.70 \pm 1.06$ & $10.67 \pm 1.32$ & 0.004 \\
\hline Hematocrit (\%) & $29.02 \pm 2.83$ & $31.75 \pm 3.84$ & 0.004 \\
\hline Sodium (mEq/l) & $137.91 \pm 2.78$ & $138.05 \pm 3.08$ & 0.750 \\
\hline Potassium (mEq/l) & $3.85 \pm 0.31$ & $3.92 \pm 0.34$ & 0.281 \\
\hline Chlorine (mEq/l) & $105.2 \pm 3.13$ & $105.21 \pm 3.21$ & 0.688 \\
\hline Total protein $(\mathrm{g} / \mathrm{dl})$ & $4.90 \pm 0.59$ & $5.07 \pm 0.51$ & 0.120 \\
\hline Albumin (g/dl) & $2.81 \pm 0.39$ & $2.96 \pm 0.39$ & 0.129 \\
\hline Blood urea nitrogen (mg/dl) & $12.18 \pm 2.74$ & $11.84 \pm 3.59$ & 0.466 \\
\hline Creatinine (mg/dl) & $0.68 \pm 0.16$ & $0.65 \pm 015$ & 0.559 \\
\hline Total bilirubin (mg/dl) & $0.91 \pm 0.35$ & $0.96 \pm 0.41$ & 0.614 \\
\hline Aspartate aminotransferase (IU/l) & $27.45 \pm 8.49$ & $25.88 \pm 9.10$ & 0.312 \\
\hline Alanine aminotransferase (IU/l) & $15.32 \pm 9.46$ & $14.17 \pm 6.22$ & 0.944 \\
\hline
\end{tabular}

$\mathrm{SD}$, standard deviation.

delirium has been reported to occur in $15-33.3 \%$ of patients undergoing surgery for oral cancer (18-21). Makiguchi et al reported the incidence of postoperative delirium to be $33.3 \%$ in patients undergoing free flap reconstruction for oral cancer (21). In the present study, $21.2 \%$ of patients underwent reconstructive surgery for oral cancer, which is a slightly lower proportion than in previous studies (21). The reason for this is that our study included not only patients undergoing free flap surgery but also those in whom a pedicle flap was used; of note, there was a significant difference in the incidence of postoperative delirium between these two groups of patients (10.2 vs. $30.9 \%$, $\mathrm{P}=0.008)$.
We investigated the preoperative, intraoperative, and postoperative factors associated with the occurrence of postoperative delirium. There is some evidence indicating that older age, male sex, and tobacco and alcohol consumption are risk factors for postoperative delirium (7,22-24). Kuo et al showed that the flap survival rate decreased significantly in 1,364 patients with alcohol-induced psychiatric disorders who had undergone microsurgical tissue transfer after resection of head and neck cancer. They concluded that treatment requires a multidisciplinary approach and intensive medical care (25). In our study, there were no significant correlations between any of the above-mentioned risk factors and postoperative 
Table VI. Multiple analyses of clinical factors for postoperative delirium.

\begin{tabular}{lcccr}
\hline & & \multicolumn{2}{c}{$95 \% \mathrm{CI}$} & P-value \\
\cline { 3 - 4 } Factor & Odds ratio & Lower & Upper & 0.565 \\
\hline Operating time & 0.995763819 & 0.980508483 & 1.010068605 & 0.716 \\
Anesthesia time & 1.002825715 & 0.987937462 & 1.019166308 & 0.577 \\
Blood loss & 1.000671161 & 0.998370621 & 1.003225717 & 0.057 \\
Method of reconstruction & 3.513929237 & 0.96294838 & 15.84227166 & 0.005 \\
Postoperative ambulation & 0.556898667 & 0.34378401 & 0.845526695 & 0.380 \\
Red blood cell count & 3.517797785 & 0.215899261 & 58.37353116 & 0.639 \\
Hemoglobin & 1.505387938 & 0.273554244 & 8.796271166 & 0.951 \\
Hematocrit & 0.980221207 & 0.515291584 & 1.873642604 & \\
\hline
\end{tabular}

CI, confidence interval.

delirium in the univariate analysis, which is consistent with some earlier reports $(16,20)$.

The univariate analysis of intraoperative and postoperative risk factors revealed a significant correlation between postoperative delirium and operating time $(\mathrm{P}=0.033)$, duration of anesthesia ( $\mathrm{P}=0.039)$, amount of blood loss $(\mathrm{P}=0.027)$, method of reconstruction $(\mathrm{P}=0.008)$, type of flap used $(\mathrm{P}=0.009)$, and time to ambulation after surgery $(\mathrm{P}=0.0008)$; however, there was no significant correlation with blood transfusion, tracheotomy, or flap engraftment. Yamagata et al performed multivariate analyses and found that the risk increased significantly when the operating time was longer than $10 \mathrm{~h}$ (18). Our results are similar to those of earlier studies showing that longer operating and anesthesia times increase the risk of postoperative delirium. In this study, we found a significantly higher incidence of postoperative delirium in patients undergoing free flap reconstruction $(30.9 \%)$ than in those undergoing pedicle flap reconstruction (10.0\%); the highest rate was in patients undergoing forearm flap (37.5\%) or scapular osteocutaneous flap (33.3\%) reconstruction. Unlike other types of flap reconstruction, a forearm flap procedure involves multiple surgical sites, including the site on the forearm from which the skin is harvested for the graft, so patient mobility is restricted postoperatively. The longest operating and anesthesia times in our study were for scapular osteocutaneous flap reconstruction. In general, compared with patients undergoing a pedicle flap reconstruction, those undergoing free flap reconstruction tended to require prolonged bed rest to protect the anastomosed vessels. This might explain why postoperative delirium was so common in patients who underwent forearm flap and scapular osteocutaneous flap reconstruction, and may also explain why postoperative delirium occurs more often in patients undergoing free flap reconstruction than in those undergoing pedicle flap reconstruction.

Since 2009, our department has promoted ambulation on the second postoperative day for patients with oral cancer undergoing tumor resection with reconstruction. The mean number of days until postoperative ambulation has decreased from 4.6 to 3.1 days, and as a result, the occurrence of postoperative delirium has decreased from 29.2 to $14.0 \%$. Moreover, multivariate logistic regression analysis in our study showed a significant correlation between early postoperative ambulation and a decreased risk of postoperative delirium. Early postoperative ambulation may be the reason our incidence of postoperative delirium is lower than that reported by Makiguchi et al (21). It is noteworthy that the rate of postoperative delirium in our non-early ambulation group was similar to that reported previously (21). In the past, bed rest after reconstructive surgery for oral cancer was considered important; however, recent reports have indicated that admission to the ICU after reconstructive surgery for head and neck cancer does not contribute to flap survival (26). In support of this, the promotion of early ambulation did not affect the flap survival in this study. Postoperative delirium has a temporal and etiologic relationship with surgery and usually develops between postoperative days 2 and 7 (27). Consistent with previous reports $(3,6,20)$, our results showed that the mean onset of postoperative delirium was $2.5 \pm 1.0$ days after surgery, and it developed in less than 3 days in $86.4 \%$ of cases. Therefore, promoting early postoperative ambulation is critical for the prevention postoperative delirium. There have been several recent reports on the benefits of early postoperative ambulation across a number of surgical disciplines (28-32). These benefits include a reduced risk of respiratory complications, improved circulation, prevention of deep vein thrombosis and pulmonary embolism, and improved psychologic well-being. Consequently, early postoperative ambulation decreases the perioperative complications and contributes to a reduction in medical costs (4).

We found a close association between certain hematologic parameters and the risk of postoperative delirium. Patients with postoperative delirium had more hemorrhage than those without delirium, and as a result, postoperative blood tests revealed a decrease in hemoglobin, red blood cells, and hematocrit. Previous reports have similarly shown a relationship between decreased red blood cell count, hemoglobin, and hematocrit values as a result of blood loss and increased risk of postoperative delirium (18-20,23-25). Blood loss during surgery decreases the oxygen supply to the brain, which causes cerebral ischemia. There has been a suggestion that a decreased oxygen supply plays an important role in certain types of mental illness (33). However, the relationship between hematologic parameters and the risk of postoperative delirium remains controversial. 
Our study has some limitations. First, it was retrospective in nature, so we cannot exclude the possibility of confounding factors. Second, the sample size was small. Third, it was not possible to compare the results of our study with those of others because there have been few previous reports specifically focusing on the risk of postoperative delirium, or other postoperative complications such as aspiration pneumonia and deep vein thrombosis, in patients undergoing tumor resection with reconstruction for oral cancer. Prospective multicenter randomized investigations in larger numbers of patients with longer follow-up durations are required to confirm our results. Fourth, this study did not examine in detail the benefits of early postoperative ambulation other than preventing delirium. The length of hospital stay varied depending on the presence or absence of postoperative treatment, such as chemotherapy and/or radiotherapy. Moreover, because the discharge criteria for swallowing, pronunciation, and neck and upper limb rehabilitation were not clear, we did not examine the length of hospital stay. Fifth, the study examined the patients' history of mental disorders, but not of other systematic diseases such as hypertension, diabetes, or obesity. Further, we were unable to finish the character analysis and psychoanalysis of every patient before surgery. We would like to examine these points in our future research.

This study is an early attempt to identify clinical risk factors for postoperative delirium in patients who have undergone tumor resection and reconstruction for oral cancer. Our findings indicate that delayed postoperative ambulation is a significant risk factor for postoperative delirium. We advocate the promotion of early postoperative ambulation because it enhances recovery and prevents a number of postoperative complications.

\section{Acknowledgements}

Not applicable.

\section{Funding}

The study was supported by the Japan Society for the Promotion of Science KAKENHI (grant no. 19K19204).

\section{Availability of data and materials}

The datasets used during the present study are available from the corresponding author upon reasonable request.

\section{Authors' contributions}

AH, MS and HNakay conceived and designed the study. NT obtained most of the data and wrote the manuscript. YM, TT, YO, JS, HNakas and HA extracted the data. RY, KK and $\mathrm{MN}$ performed the statistical analysis. All authors read and approved the final manuscript.

\section{Ethics approval and consent to participate}

The study protocol was approved by the institutional review board of Kumamoto University (RINRI no. 1928) and conducted in accordance with the Declaration of Helsinki. The requirement for informed consent was waived in view of the retrospective design of the study. However, patients were given the opportunity to decline participation via the opt-out route.

\section{Patient consent for publication}

Not applicable.

\section{Competing interests}

The authors declare that they have no competing interests.

\section{References}

1. Dittmer DK and Teasell R: Complications of immobilization and bed rest. Part 1: Musculoskeletal and cardiovascular complications. Can Fam Physician 39: 1428-1432, 1435-1427, 1993.

2. Teasell R and Dittmer DK: Complications of immobilization and bed rest. Part 2: Other complications. Can Fam Physician 39: 1440-1442, 1445-1446, 1993.

3. Takeuchi M, Takeuchi H, Fujisawa D, Miyajima K, Yoshimura K, Hashiguchi S, Ozawa S, Ando N, Shirahase J, Kitagawa Y and Mimura M: Incidence and risk factors of postoperative delirium in patients with esophageal cancer. Ann Surg Oncol 19: 3963-3970, 2012.

4. Lipowski ZJ: Transient cognitive disorders (delirium, acute confusional states) in the elderly. Am J Psychiatry 140: 1426-1436, 1983.

5. Francis J, Martin D and Kapoor WN: A prospective study of delirium in hospitalized elderly. JAMA 263: 1097-1101, 1990

6. Inouye SK, Van Dyck CH, Alessi CA, Balkin S, Siegal AP and Horwitz RI: Clarifying confusion: The confusion assessment method. A new method for detection of delirium. Ann Intern Med 113: 941-948, 1990.

7. Marcantonio ER, Goldman L, Mangione CM, Ludwig LE, Muraca B, Haslauer CM, Donaldson MC, Whittemore AD, Sugarbaker DJ, Poss R, et al: A clinical prediction rule for delirium after elective noncardiac surgery. JAMA 271: 134-139, 1994.

8. Edlund A, Lundström M, Lundström G, Hedqvist B and Gustafson Y: Clinical profile of delirium in patients treated for femoral neck fractures. Dement Geriatr Cogn Disord 10: 325-329, 1999.

9. Williams-Russo P, Urquhart BL, Sharrock NE and Charlson ME: Post-operative delirium: Predictors and prognosis in elderly orthopedic patients. J Am Geriatr Soc 40: 759-767, 1992.

10. Aldemir M, Ozen S, Kara IH, Sir A and Bac B: Predisposing factors for delirium in the surgical intensive care unit. Crit Care 5: 265-270, 2001.

11. Benoit AG, Campbell BI, Tanner JR, Staley JD, Wallbridge HR, Biehl DR, Bradley BD, Louridas G, Guzman RP and Fromm RA: Risk factors and prevalence of perioperative cognitive dysfunction in abdominal aneurysm patients. J Vasc Surg 42: 884-890, 2005.

12. Papaioannou A, Fraidakis O, Michaloudis D, Balalis C and Askitopoulou $\mathrm{H}$ : The impact of the type of anaesthesia on cognitive status and delirium during the first postoperative days in elderly patients. Eur J Anaesthesiol 22: 492-499, 2005.

13. Guo Y, Jia P, Zhang J, Wang X, Jiang H and Jiang W: Prevalence and risk factors of postoperative delirium in elderly hip fracture patients. J Int Med Res 44: 317-327, 2016.

14. Hammeke TA and Hastings JE: Neuropsychologic alterations after cardiac operation. J Thorac Cardiovasc Surg 96: 326-331, 1988.

15. Smith LW and Dimsdale JE: Postcardiotomy delirium: Conclusions after 25 years? Am J Psychiatry 146: 452-458, 1989.

16. Dyer CB, Ashton CM and Teasdale TA: Postoperative delirium. A review of 80 primary data-collection studies. Arch Intern Med 155: 461-465, 1995.

17. Lee KH, Ha YC, Lee YK, Kang H and Koo KH: Frequency, risk factors, and prognosis of prolonged delirium in elderly patients after hip fracture surgery. Clin Orthop Relat Res 469: 2612-2620, 2011.

18. Yamagata K, Onizawa K, Yusa H, Wakatsuki T, Yanagawa T and Yoshida H: Risk factors for postoperative delirium in patients undergoing head and neck cancer surgery. Int J Oral Maxillofac Surg 34: 33-36, 2005. 
19. Shiiba M, Takei M, Nakatsuru M, Bukawa H, Yokoe H, Uzawa K and Tanzawa $\mathrm{H}$ : Clinical observations of postoperative delirium after surgery for oral carcinoma. Int J Oral Maxillofac Surg 38: 661-665, 2009

20. Hasegawa T, Saito I, Takeda D, Iwata E, Yonezawa N, Kakei Y, Sakakibara A, Akashi M, Minamikawa T and Komori T: Risk factors associated with postoperative delirium after surgery for oral cancer. J Craniomaxillofac Surg 43: 1094-1098, 2015.

21. Makiguchi T, Yokoo S and Kurihara J: Risk factors for postoperative delirium in patients undergoing free flap reconstruction for oral cancer. Int J Oral Maxillofac Surg 47: 998-1002, 2018.

22. Marcantonio ER, Goldman L, Orav EJ, Cook EF and Lee TH: The association of intraoperative factors with the development of postoperative delirium. Am J Med 105: 380-384, 1998.

23. Sasajima Y, Sasajima T, Uchida H, Kawai S, Haga M, Akasaka N, Kusakabe M, Inaba M, Goh K and Yamamoto H: Postoperative delirium in patients with chronic lower limb ischaemia: What are the specific markers? Eur J Vasc Endovasc Surg 20: 132-137, 2000.

24. Schneider F, Böhner H, Habel U, Salloum JB, Stierstorfer A, Hummel TC, Miller C, Friedrichs R, Müller EE and Sandmann W: Risk factors for postoperative delirium in vascular surgery. Gen Hosp Psychiatry 24: 28-34, 2002.

25. Kuo YR, Jeng SF, Lin KM, Hou SJ, Su CY, Chien CY, Hsueh KL and Huang EY: Microsurgical tissue transfers for head and neck reconstruction in patients with alcohol-induced mental disorder Ann Surg Oncol 15: 371-377, 2008.

26. Nkenke E, Vairaktaris E, Stelzle F, Neukam FW and Pierre MS: No reduction in complication rate by stay in the intensive care unit for patients undergoing surgery for head and neck cancer and microvascular reconstruction. Head Neck 31: 1461-1469, 2009.
27. Fricchione GL, Nejad SH, Esses JA, Cummings TJ Jr, Querques J, Cassem NH and Murray GB: Postoperative delirium. Am J Psychiatry 165: 803-812, 2008.

28. Bardram L, Funch-Jensen P, Jensen P, Crawford ME and Kehlet H: Recovery after laparoscopic colonic surgery with epidural analgesia, and early oral nutrition and mobilisation. Lancet 345: 763-764, 1995.

29. How do stroke units improve patient outcomes? A collaborative systematic review of the randomized trials. Stroke Unit Trialists Collaboration. Stroke 28: 2139-2144, 1997.

30. Basse L, Raskov HH, Hjort Jakobsen D, Sonne E, Billesbølle P, Hendel HW, Rosenberg J and Kehlet H: Accelerated postoperative recovery programme after colonic resection improves physical performance, pulmonary function and body composition. Br J Surg 89: 446-453, 2002.

31. Khoo CK, Vickery CJ, Forsyth N, Vinall NS and Eyre-Brook IA: A prospective randomized controlled trial of multimodal perioperative management protocol in patients undergoing elective colorectal resection for cancer. Ann Surg 245: 867-872, 2007.

32. Das-Neves-Pereira JC, Bagan P, Coimbra-Israel AP, GrimaillofJunior A, Cesar-Lopez G, Milanez-de-Campos JR, Riquet M and Biscegli-Jatene F: Fast-track rehabilitation for lung cancer lobectomy: A five-year experience. Eur J Cardiothorac Surg 36: 383-391, 391-382, 2009

33. van der Mast RC, van den Broek WW, Fekkes D, Pepplinkhuizen $L$ and Habbema JD: Incidence of and preoperative predictors for delirium after cardiac surgery. J Psychosom Res 46: 479-483, 1999. 